\title{
O MUSEU PAULISTA DA USP E A MEMÓRIA DA INDEPENDÊNCIA
}

\author{
Cecilia Helena de Salles Oliveira*
}

\begin{abstract}
O objetivo deste artigo é discutir os vínculos entreo Museu Paul ista da usp e o movimento de construção e atualização da memória da I ndependência, problematizando-se por meio des sas relações o papel pedagógico assumido pela instituição, particularmente na primeira metade do século XX. Pretendese desse modo contribuir para a reflexão sobrea maneira pela qual um museu de história pode ser interpretado como "lugar de memória" e como espaço para a formulação e encaminhamento de problemas históricos.
\end{abstract}

Palavraschave Museu Paulista. Memória. Independêndia. História.

The Paulista Museum at usp and the memory of Independence

ABSTRACT: This paper is aimed at discussing the links between the Paulista M useum at theUniversity of São Paulo and the construction and updating processes of the memory of Independence It also focuses on the pedagogic role this Institution played, mainly during the first half of the XX century. It thus intends to contribute to the comprehension of museums of history as "places of memory" and as spaces where historical problems are formulated and dealt with.

Key words Paulista M useum. Memory. Independence History.

* Museu Paulista da Universidade de São Paulo (USP). 
ão bastante conhedidas as vinaulações entre o Museu Paulista da usp e as práticas celebrativas que cercam a independência do Bra sil. Todos os anos, no dia de 7 de setembro, simultaneamente a desfiles e comemorações oficiais, o Parque da Independência, no bairro do I piranga, em São Paulo, recebe significativo contingente de pes soas que ali se concentra, apropriando-se dos jardins e do espaço público, para visitar e reverenciar a Casa do Grito e o Museu, assim como a cripta, localizada no Monumento ao Centenário de 1922, onde estão depositados os restos mortais de D. Pedro, de Da. Leopoldina e de Da. Amélia.

No entanto, do mesmo modo como essas manifestações se re vestem de complexidade muito maior do que à primeira vista fazem supor, as relações entre o Museu Paulista e a independência também apresentam importantes particularidades a serem consideradas. Abordálas significa reconhecer, antes de tudo, que se situam no âmbito do movimento histórico e político de conformação da memória da independência e de construção da data de 7 de setembro de 1822 como marco da história nacional, processo que se desdobrou durante todo o século XIX, em consonância com o delineamento da Monarquia Constitucional e do Estado Nacional, e que assumiu contornos ainda mais singulares quando da organização da República.

Ou seja, ao contrário daquilo que freqüentemente se imagina a proclamação do príncipe D. Pedro, na colina do I piranga e às margens do riacho do mesmo nome, não teve repercussão no momento de sua ocorrência. Além de não merecer acolhida especial da parte dos inúmeros e atuantes jornais que circulavam na Corte do Rio de Janejro e em várias outras regiões do então Reino do Brasil, a da também não se referiram os membros do governo da Regência e tampouco foi àquela época interpretada como baliza definidora do curso da história Nem mesmo D. Pedro na Carta dirigda aos paulistas datada de 8 de setembro, deixou registros espeć́ficos a respeito do episódio do dia anterior. ${ }^{1}$ No documento, a expressão "Independência ou morte", Ionge de referenciar um evento memorável ou uma situação consumada e irreversível, apresentava o caráter de palavra de ordem e sua contundência estava entrelaçada muito mais à possibilidade efetiva, naquela ocasião, da deflagração de uma guerra civil que a uma decisão que determinava um suposto desfecho para circunstâncias tão nuança das quanto aquelas. Isso evidencia, conforme tem sugerido a mais re cente produção historiográfica sobre o tema, que, em fins de 1822, as condições políticas e os enfrentamentos sodiais estavam imbricados com 
questões, debates e lutas armadas cuja complexidade e amplitude superam tanto a consagrada controvérsia entre as cortes em Lisboa e o governo sediado no Rio de Janeiro quanto a recortada discussão em torno da união ou da separação em relação a Portugal.2

Neste sentido, da mesma forma como vem sendo profundamente interrogado o processo histórico em andamento no início do século XIX, cabe questionar a sacralizada associação entre a data de 7 de se tembro, a colina do I piranga e a Proclamação da Independência, problematizando-se, por essa via, o modo pelo qual o Museu Paulista e sua trajetória institucional se inscreveram no movimento de delimitação espacial e temporal do episódio que teria promovido o "nasdimento da nação".

\section{A construção política da data de 7 desetembro}

A proposta de considerar-se a data de 7 de setembro como dia de festa nacional comemorativo do "aniversário da independência bra sileira", em todo o território do Império, surgiu, pela primeira vez, em setembro de 1823, durante as discussões travadas na Assembléa Constituinte e coincidiu com a iniciativa aventada por membros do governo da província de São Paulo de erguer-se um monumento em memória ao ocorrido no "lugar denominado Piranga". Entretanto, ne nhuma das duas proposições chegou a concretizar-se Em razão dos desdobramentos provocados pela dissolução da Assembléia, pela outorga da Constituição de 1824 e pela Confederação do Equador, esse debate foi retomado apenas em 1826, sendo significativo o fato de que, entre 1822 e 1825, a data de 7 de setembro sequer figurou no calendário de celebrações do Império, entre as quais se encontravam o Dia do Fico, 9 de janeiro, e o dia 12 de outubro, natalício de D. Pedro e data de sua adamação popular como imperador.

Foi em 1826 que o Parlamento aprovou, em sua primeira legislatura, a introdução do 7 de setembro na categoria de "festivida de nacional". E é importante lembrar que essa decisão verificou-se sob circunstâncias bastante peculiares, pois foi imediatamente posterior à formalização dos tratados diplomáticos de reconhecimento da independência e concomitante à divulgação do relato detalhado de uma testemunha ocular - o padre Belchior Pinheiro Ferreira - das ocorrências que tiveram lugar no I piranga quatro anos antes. Primeira crônica dessa natureza a ser veiculada, tornou-se referência para a reconstituição da cena do "grito" no século XIX, uma vez que, somente 
na década de 1860, dois outros integrantes da comitiva de $D$. Pedro - o tenente Canto e Mello, pai da Marquesa de Santos, e o corone Marcondes - tornaram públicas suas rememorações, pouco acrescentando, porém, à descrição feita por Bedchior. ${ }^{3}$

Concisa e concentrando-se nos instantes imediatos que cercaram o ato da prodamação, a narrativa recuperou o momento em que o príncipe e seus companheiros de viagem se encontraram com os mensageiros vindos do Rio de Janeiro, procurando fixar a reação do jovem regente às notícias contidas nas mensagens que recebeu. Em meio a gestos movidos pela "raiva" e pelo impulso em não aceitar a "escravidão" e a "perseguição" que pareciam emanar das decisões dos deputados em Lisboa, D. Pedro, num ato dramático de vontade individual, teria arrancado do chapéu o laço azul e branco, śmbolo estabelecido pelas cortes, desembainhado a espada e se decidido pela separação de Portugal, sendo imitado por toda a comitiva

Registro fundamental na conformação da memória do 7 de se tembro, em termos do significado conferido à data e ao lugar, essa crônica recriou o episódio selando a associação entre independência e se paração de Portugal ao mesmo tempo em que minimizou confrontos, reduzindo-os à atuação das cortes, atribuiu caráter heróico ao "grito" e a seu autor. De forma muito oportuna reabilitava a imagem de D. Pedro, já que nessa ocasião o imperador enfrentava oposições e via sua popularidade esgarçar-se, seja na Câmara dos Deputados, seja na imprensa, em virtude, principalmente, de seu envolvimento na sucessão do trono português e do encaminhamento dado aos conflitos na re gião do Prata

Pouco tempo depois, essa versão ganhou o estatuto de acontecimento histórico inquestionável com a publicação da História dos principais sucessos do Império do Brasil, elaborada por José da Silva Lisboa, Visconde de Cairu, em cumprimento à solicitação feita pelo próprio imperador, obra esta a ele dedicada ${ }^{4}$ Composta por quatro tomos, editados entre 1827 e 1830, essa narrativa se fundamentou em cuidadosa coleta, disposição e leitura de documentos e constituiu a primeira interpretação circunstanciada sobre a separação de Portugal e sobre os eventos que definiram a adamação do príncipe e do Império. Texto político, a História tornou-se fonte de consulta e referência para a produção historiográfica do século XIX e segura mente serviu de inspiração tanto para a interpretação de Varnhagen, escrita na década de 1870, quanto para que, nos fins do século, Pedro Américo retratasse a cena do "grito", na tela que se tornou a repre 
sentação emblemática do episódio do I piranga. Erudição e aparente neutralidade foram recursos mobilizados por Silva Lisboa para a criação dessa obra indissoluvelmente imbricada com a luta política $\mathrm{Na}$ ocasião senador do Império e homem público de grande prestígio, havia participado da reorganização da monarquia portuguesa no Rio de Janeiro e atuara diretamente na defesa da proposta separatista e da opção monárquica Experiência política, saber acumulado e acesso à diversificada documentação sustentaram uma reconstituição linear da dinâmica dos acontecimentos pautada pela inevitabilidade da separação, que foi explicada a partir do desenvolvimento social e cultural promovido pelo governo joanino e como decorrência da atuação "arbitrária" das cortes em Lisboa. Mas, ao lado disso, Silva Lis boa ressaltou a atitude vanguardeira e predestinada de D. Pedro, figura talhada desde a infância para ser um monarca constitucional e que por suas qualidades individuais fora capaz de intervir na escrita da história e determinar a ruptura com o reino europeu sem que, segundo o autor, a continuidade institucional fosse quebrada.

Apaziguando os conflitos, situou-os no interior de uma oposição formal entre "brasileiros" e "portugueses europeus", entre "monarquistas" e "recolonizadoras cortes de Lisboa". De forma acurada, desenhou os protagonistas e dissolveu o movimento matizado de lutas políticas e sociais que ainda se desdobrava à época da publicação da obra $\mathrm{E}$, enquanto o espaço no qual se desenrolava a política foi preenchido pela imagem do jovem governante, a sucessão de eventos obedeceu a rigorosa cronologia na qual se destacam cinco momentos considerados como decisivos: 1808 (a chegada da Corte portuguesa ao Rio de Janeiro); 1820 (revolução em Portugal); 1821 (juramento de D. João VI à futura Constituição elaborada pelas cortes em Lisboa e início da Regência de D. Pedro); 7 de setembro de 1822 (prodamação da Independência pelo príncipe e abertura de "nova era" para o Brasil); e 12 de outubro de 1822 (coroamento do 7 de setembro com a adlamação pública do imperador).

Até hoje a memória dos episódios formulada por Lisboa re percute em livros didáticos e obras de divulgação, especialmente no tocante à cronologia, à imagem heróica conferida ao príncipe e à concepção de que a separação de Portugal era algo inevitável. Mas isso não quer dizer que essa versão tenha sido única ou que tenha direcionado o debate em torno da independência e de suas significações. Pelo contrário, em 1831, quando da abdicação do impera dor, o tema foi novamente recuperado, dessa vez pelos protagonistas 
do 7 de abril, transformando-se em arma de oposição a D. Pedro, como se só então a liberdade política e a emergência da nação, pre conizadas em 1822, pudessem se consolidar.

Ao longo do século XIX forjaram-se múltiplas e dissonantes memórias sobre esse momento. Tema da história e da política, a independência - à qual se encontravam atreladas questões como as da cidadania, da participação popular e da natureza do Estado Nacional e da Monarquia Constitucional - foi reavivada de forma recorrente, seja na fala de liberais, seja na fala de conservadores, adquirindo sentidos particulares dependendo das condições da luta política e do lugar social ocupado por quem a rememorava $E$ na década de 1870, quando da organização de agremiações republicanas, ao mes mo tempo em que se retomou, sob condições singulares, a discussão sobre o caráter da Monarquia, o exercício do Poder Moderador, a centralização político-administrativa e a origem da nação, recriaram-se também versões outras acerca do movimento de independência, da data de 7 de setembro e do percurso histórico do Império.

Neste sentido, na segunda metade do século XIX, o comple xo universo de representações sobre o passado abrigava versões contraditórias e, ainda que seja possível estabelecer articulações entre elas, é preciso reconhecer que não apresentam linearidade, pois que iluminadas pelas circunstâncias precisas do momento de sua produção. Assim, ao passo que em textos literários das décadas de 1850 e 1860, como os de Paulo Antônio do Valle, o 7 de setembro aparecia identificado ao momento em que, do alto da colina do I piranga, "D. Pedro protestou pelo direito sagrado da liberdade de um povo oprimido", o periódico paulistano O Polichinello, em 1876, observava que "o 7 de setembro é a página mais sombria que se pode escrever no livro de uma História Nacional; é a eterna condenação de um povo inteiro porque consentiu que no séo livre e democrático da América se assentasse um trono..."."

Mas foi precisamente nesse período que a conformação da me mória da independência adquiriu outras dimensões com a concretização de propostas concernentes à construção de monumentos que viessem a imortalizar a data de "fundação da nação" e a figura de D. Pedro I. Entre as décadas de 1860 e 1880, assistiu-se à transposição de regis tros escritos e de tradições orais para suportes materiais, capazes de resguardar do "esquecimento" evento e personagem $E$, também neste âmbito, a imagem a ser perpetuada assim como as providências para a realização das obras - especificamente a estátua eqüestre de D. Pedro 
I no Rio de Janeiro e o Monumento do I piranga em São Paulo - imbricaram-se com os ditames das disputas político-partidárias.

Isso não quer dizer que, té então, não se houvessem enraizado práticas celebrativas, seja em relação à data, seja em relação ao lugar da prodlamação, ou que gramuras e pinturas não se tivessem detido sobre o episódio. Ao menos em São Paulo, há informações a respeito de festividades redizadas no "ś́tio do I piranga" durante as décadas iniciais do século XX e, conforme descrição de Manue Eufrázio de Azeve do Marques, nos Apontamentos para a história da provínia de São Paur lo (consta outro nome na nota abaixo!?) desde 1825 o provável local da prodamação fora assinalado por marco em pedra ${ }^{6}$ Em contra partida, o "aniversário" da independência era geralmente comemora do com um Te Deum patrocinado pelas câmaras municipais e, em vá rios anos ao longo do Império, a data de 7 de setembro coincidiu com eleições parlamentares. Além disso, havia registros iconográficos sobre D. Pedro e sobre o ato da independência, a exemplo da pintura confeccionada em 1844 pelo artista francês François-René M oreaux, pertencente ao acervo do Museu Imperial em Petrópolis.

Entretanto, como sugeriu Pierre Nora, na introdução à cole tânea Les Lieux des Mémai res ${ }^{7}$ os monumentos jogaram peso decisivo na configuração da memória nacional no século XIX, pois expressa vam a intenção deliberada, por parte de segmentos políticos definidos, de defender do movimento indetermi nado da história fragmentos do passado reconstituídos por intermédio de abordagens e focos pre cisos. Neste sentido, assumindo a configuração de "lugares de me mória", na feliz concepção do historiador, os monumentos não foram obras pacificamente ideal izadas, e sim construções destinadas a resguardar poderes e saberes sobre o passado e sobre as origens da nação que se achavam ameaçados pela própria complexidade do curso da história e da política.

A estátua eqüestre de D. Pedro I inaugurada, em 1862, na Praça da Constituição (hoje Praça Tiradentes), no Rio de Janeiro, sugere não só a projeção de memória singular acerca da prodamação de 7 de setembro como indica, com clareza, a imbricação entre política e construção da memória nacional.

O plano de construir na Corte um monumento em homena gem à independência e ao imperador começou a ser posto em exe cução entre 1852 e 1854 e retomava iniciativa infrutífera lançada pela Câmara carioca por volta de 1825. Ao lado da abertura de subs crição voluntária para que os “cidadãos" da cidade e do I mpério con- 
tribuíssem com os custos da obra, vários artistas foram convidados a participar do concurso que deveria eleger o projeto estético e histórico considerado como mais adequado. Em 1856, foi selecionada a concepção escultural - idealizada por João Maximiano Mafra, professor da Academia Imperial de Belas-Artes e construída pelo escultor francês Louis Rochet - que celebra, simultaneamente, o "grito" do I piranga e a outorga da Constituição, e que expõe a figura de D. Pedro I sobre um cavalo, no ato da declaração de 1822, e segurando nas mãos a Carta de 1824, acima de uma base na qual se agregaram quatro agrupamentos menores, compostos por índios e animais re presentando os rios Amazonas, Madeira, Paraná e São Francisco. ${ }^{8}$

Inicial mente prevista para 12 de outubro de 1859, a solenidade de inauguração foi sendo sucessivamente transferida e, por fim, deveria realizar-se a 25 de março de 1862, celebrando-se os 40 anos de independência no dia em que se rememorava a outorga da Cons tituição do I mpério. No entanto, em razão da chuva intensa, mais uma vez a homenagem foi adiada

Em seu Diário, D. Pedro II assinalou os "desgostos" e as "contrariedades" ensejados pelos inúmeros artigos publicados nos jornais fluminenses contra a escultura, entre os quais um em especial, escrito pelo político liberal Teóphilo Ottoni, que apelidou a estátua de "mentira de bronze". Preocupavam-no as implicações da solenidade por um lado, orientou o gabinete conservador, chefiado por Caxias, a adiar o evento, temendo que as oposições - naquele momento tanto de liberais quanto de dissidências conservadoras - explorassem o fato de o governo não avaliar o estrago da chuva na saúde e "bolsa" dos espectadores da festa, ou acusassem o gabinete de valer-se da chuva para impedir "grande ajuntamento de povo" por "receio" de manifestações contrárias. Ao mesmo tempo, o imperador temia que, caso o mau tempo se prolongasse, a cerimônia ficasse irremediavelmente comprometida pela proximidade do 7 de abril. ${ }^{9}$

Transferida para o domingo 30 de março, a festividade sugere a impossibilidade de dissociar representação alegórica, significações históricas e circunstâncias políticas. E isso se evidencia também pelo discurso que Nabuco de Araújo proferiu naquela ocasião. Reconhe cendo na estátua a consagração da memória de "dois fatos", a Inde pendência e a Constituição, este político, polemizando com seus aliados conservadores e com adversários em ambos os partidos, deixou claro, porém, que não se tratava da glorificação de um reinado ou da apoteose de uma época e muito menos obra da "reação" ou da 
"contrarevolução". Como não vincular essas expressões ao momento particular em que se manifestava a chamada Liga Progressista e em que os partidos liberal e conservador encontravam-se em movimento de redefinição? De que maneira desvincular a solenidade, bem como o intuito do gabinete conservador e de D. Pedro II de patrocinála, das disputas mais amplas que colocavam sob o divo da crítica tanto o passado quanto o próprio sistema constitucional vigente?

\section{Um monumento no I piranga: demarco cel ebrativo a M useu Paulista}

Questões dessa mesma natureza podem ser levantadas em re lação aos debates e desencontros que assinalaram a construção do Monumento do I piranga em São Paulo, palácio majestoso que, ide alizado e erguido na década de 1880, demarcou definitivamente 0 lugar da prodamação de 7 de setembro, assinalando, de forma ima ginária, o ponto a partir do qual teria se originado a nação.

Ou seja, também nesse caso, foram circunstâncias políticas complexas e ainda não completamente desvendadas que, na Corte e em São Paulo, sustentaram a concretização de proposta já discutida inúmeras vezes ao longo do Império, mas sempre rechaçada sob a problemática alegação da falta de recursos financeiros. Basta lembrar, neste sentido, que a "questão do I piranga", como foi chamada por vários órgãos da imprensa paulista, a exemplo de A Província de São Paulo, foi se definindo, principalmente entre 1885 e 1890, período da construção do edifício-monumento, simultaneamente à intensificação da propaganda republicana e aos nuançados desdobramentos político-partidários do debate em torno da emancipação dos es cravos, do movimento abolicionista e da imigração.

Os políticos e capitalistas que patrocinaram a realização do Monumento, entre os quais se encontrava o advogado e professor da Faauldade de Direito, Joaquim I gnácio de Ramaho, parecem ter contado com o apoio sempre atuante de D. Pedro II em favor da obra, aja concepção arquitetônica e estética se deveu ao arquiteto e engenheiro italiano Tommazzo Bezi, projeto e personagem que se constituíram em outra fonte de polêmicas. $E$ das controvérsias em torno do palácio também não escapou o atista Pedro Américo de Figueiredo e Melo, contrata do, em 1886, para elaborar a tela "Independência ou Morte", especialmente destinada para figurar no Saão de Honra do edifício e comple mentar a representação simbólica ensejada pelos trabalhos de alvenaria 
Sempre ameaçada, a construção do monumento, do ponto de vista da conformação da memória, era tributária em certa medida, das matizadas recriaçốes que cercaram o episódio durante o século XIX. Porém, os políticos do Partido Conservador que o conceberam revestiram-nas de dimensões inéditas que não se restringiram às linguagens espećficas com as quais procuraram traduzir e perenizar um passado irremediavelmente perdido. Para eles, vencer a "ação destruidora do tempo" e a "contrariedade dos homens", como afirmou Ramalho, que presidiu a comissão encarregada das obras, era recompor, em hora marcada por profunda avaliação da Monarquia, uma memória recortada, mas positiva, da independência, do Império e de sau fundador. E quanto a isso foram bem-sucedidos, pois o edifício resguardou o "fato independência" como nenhuma das outras rememorações havia fixado, projetando-o como fragmento temporal e espacial cuja realidade supostamente precedia qualquer interpretação.

Edificado originalmente para projetar a versão conservadora da prodlamação da independência e da fundação do Império, o palá cio-monumento adquiriu, entretanto, outros significados a partir da organização da República A memória e a tradição que atrelaram o 7 de setembro de 1822 à emergência da Monarquia reapareceram, na década de 1890, modificadas pela articulação do ato da independência ao "renascimento da nação", tal como proposto pelo ideário republicano. Apropriado em 1893 para se transformar em museu público, sustentado pelo governo do Estado de São Paulo, o monumento foi um dos suportes do entendimento, hoje banalizado, de que as origens nacionais se confundiam com o "progresso das terras paulistas", sintetizado na colina do I piranga, uma das portas de entrada da cidade de São Paulo e caminho a articular as riquezas planaltinas com o principal porto exportador em Santos.

Sob os desígnios da República, o edifício metamorfoseou-se em poderoso recurso na difusão de uma nova leitura da história na cional, o que impingiu féções peculiares à memória da independência As lideranças republicanas sustentavam o "governo do povo pelo povo", apregoando uma participação política ampliada Ao mesmo tempo, acreditavam que a viabilidade deste princípio dependia da superação da "ignorância geral da população". Assim, desse ponto de vista era imperativo "emancipar o povo", impondo-lhe uma educação preparatória da cidadania.

O Museu Paulista foi inaugurado oficialmente a 7 de setembro de 1895 e surgiu como instituição científica, voltada para a pes 
quisa e a instrução popular no campo das ciências naturais. No entanto, esse direcionamento não impediu que coleções de insetos, peixes e répteis, por exemplo, convivessem com a presença impactante da tela de Pedro Américo e com salas destinadas à apresentação de "objetos históricos" atribuídos a vultos renomados, como José de Anchieta e Martim Afonso de Souza. Além disso, a ênfase na história natura não colidia com as características de lugar privilegiado para a celebração da memória nacional.

Não foi por acaso, portanto, que a partir dessa época, em São Paulo, as festividades ćivicas em torno da independência passaram a ser realizadas no monumento-museu, inventando-se, por essa via, o ritual de peregrinação ao śtio onde o Brasil-nação teria se origina do, prática que continua sendo atualizada contemporaneamente. As sim, o majestoso prédio passou a articular significações estéticas, celebrativas, científicas e pedagógicas.

E a esse respeito são sugestivas as observações feitas por Marie Robinson Wright, em 1902:

(...) O principal ponto de atração de todos os visitantes da cidadeéo I piranga, o magnífico monumento erigido em 1885 no lugar onde foi prodamada a I ndependência do Brasil em 1822. É a mais bela realização da arquitetura brasileira, planejada não só para comemorar essegl orioso evento mas também para servir como "instituição de conhedimentos". O Museu do I piranga possui tesouros de grandeinteresse histórico ecientífico; valiosas e curiosas relíquias etambém al gumas das mel hores pinturas deartistas brasileiros $(. . .)^{10}$ mentava:

Já em 1912, outro cronista, Archibald Stevenson Forrest, co-

(...) Aos domingos e feriados, o passeio favorito do povo - italianos, negros, portugueses, alemães, paulistas eingleses - éir de carro da Pra ça da Séatéos jardins eo Museu do I piranga A viagem ocupa cerca de meia hora, e o percurso éfeito saindo-se do Largo 7 deSetembro, descendo pela rua da Glória, com suas pequenas casas uniformes, passando pelo M atadouro, e seguindo pelas al amedas arborizadas de ambos os lados e que vão em direção aos bai rros, onde os edifícios avançam em todas as direções e os operários executam suas tarefas apesar de ser domingo... A mai oria dos passage ros desce para os jardins do I piranga, situados em terreno de largas cal çadas que vai se elevando suavemente marginado por ciprestes, canteiros deflores muito bem tratados etodos os tipos de arbustos. O M useu, erigido como monumento para come morar o histórico acontecimento, éuma construção imponente ebem 
desenhada, com belas escadas el uxuosas gal erias em uma das quais está umenormequadro ilustrando o episódio "I ndependência ou M ortel..."

Estas impressões testemunham a maneira pela qual, no início do século XX, o monumento-museu havia sido incorporado ao cotidiano da cidade, servindo como local de passeios e recreio para dife renciados segmentos sociais. Além disso, nessa mesma época, torna ra-se também lugar de visitação obrigatória para professores e estudantes, como revelam as palavras do zoólogo Hermann von Ihering, primeiro diretor da instituição:

(...) O dia 7 de setembro, queo Monumento do I piranga comemora foi aqui dignamentefestejado em 1912. Graças aos efforços empregados pelo govemo, a soleni dadetevebrilho excepcional, devido ao concurso das es colas públicas queenviaram para mais de 10.000 crianças, o monumento artisticamenteomamentado bem como o grandejardim ondesearmaram barracas para os pequenos convidados, apresentavam belíssimo aspecto (...). ${ }^{12}$

No entanto, a atuação pedagógica desempenhada pelo museu ultrapassava seu caráter de agente "conservador" de um passado heróico. A prática de rememorar acontecimentos e personagens exponenciais da história do Brasil e de São Paulo davase em concomitância à exposição da natureza exuberante do país. Mediatizados por um saber dlassificatório, estavam colocados à disposição do público os mais variados exemplares da fauna e da flora paulistas e brasileiras aos quais se agre gavam rochas, minerais, vestígios arqueológicos, bem como "amostras" da cultura dos "primitivos" habitantes, grupos indígenas que teimavam em sobreviver ao avanço da "divilização".

Em uma primeira aproximação, e levando-se em conta as considerações de Circe Bittencourt sobre a "escola popular" (escola primária e ginasial) do período, é possível considerar que efetivamente o Museu Paulista representava pape importante na difusão da "história pátria", pois o ensino dessa disciplina não se limitava à sala de aula envolvendo práticas educativas públicas, como festas comemorativas e eventos des tinados a lembrar os "heróis nacionais" ${ }^{13} \mathrm{E}$ a esse respeito são significativas as palaras de José Veríssimo escritas nos fins do século XIX:

(...) Porquenão é somentenas escolas ou pelo estudo deautorese documentos quese pode estudar a história pátria... Os monumentos, os museus, as col eções arqueológicas ehistóricas, essas construções quenossosantepassados com tanta propriedade chamaram memórias, são outras tantas maneiras derecordação do passado, do ensino histórico enacional (...... ${ }^{14}$ 
Por outro lado, as comemorações, sejam as que se voltavam para a exaltação dos símbolos nacionais, como hino e bandeira, se jam as que envolviam desfiles, como no caso do 7 de setembro, possuíam raio de ação educativa mais amplo: realizadas em lugares públicos e à luz do dia serviam para "educar" e envolver pessoas que não freqüentavam os bancos escolares.

\section{O Centenário daIndependênciaeo perfil demuseu dehistória}

No entanto, a inserção do museu no âmbito das práticas pe dagógicas e das concepções políticas republicanas adquiriu novos contornos especialmente a partir da década de 1920. Nessa ocasião, - Museu Paulista, que popularmente era (e ainda é) conhedido como Museu do I piranga, começou a transformar-se em museu propria mente de história, graças às intervenções estéticas e historiográficas projetadas e consumadas por Afonso de Escragnolle Taunay, que dirigiu a instituição de 1917 a 1945.

Durante sua gestão, Taunay, com o apoio de políticos e empresá rios, foi gradualmente reorganizando as áreas expositivas, substituindo coleções zoológicas e botânicas por acervos destinados à rememoração de fatos históricos e tradições brasileiras e paul istas. Passo decisivo nessa direção foi dado quando da montagem conceitual e física da decoração interna do prédio, existente ainda hoje, e que visava a celebrar o Centenário da Independência em 1922, o que contribuiu para reforçar ainda mais os laços entre a instituição e a memória nacional.

Em linhas gerais, o conjunto figurativo, planejado com esmero, ocupa o saguão de entrada, a escadaria de mármore, os espaços que a cercam e o Salão Nobre, fazendo do eixo central do edifício um "ca minho", demarcado por episódios e personagens que representam o percurso da história de São Paulo e do Brasil, e que se inicia com a colonização encontrando seu desfecho na independêndia Sob feições teatralizadas e formais, pinturas, retratos, esculturas de mármore e bronze, bem como as ânforas de cristal contendo as águas dos prindpais rios brasileiros, compõem o cenário de um espetáculo visual, es teticamente impressionante, e que procura mobilizar sensibilidades para a "realidade objetiva" e aparentemente inquestionável do passado ali apresentado.

Da decoração fazem parte as figuras dos primeiros colonizadores das terras paulistas, os bandeirantes - dispostos na condição 
de protagonistas decisivos da definição do território e das fronteiras -, e os políticos que teriam coadjuvado D. Pedro I na concretização da obra nacional. Mas o ponto culminante é sem dúvida, o Salão Nobre onde estão reunidas a tela de Pedro Américo, os retratos de $\mathrm{Da}$ Leopoldina, Maria Quitéria, J osé Bonifácio, J oaquim Gonçal ves Ledo, J osé Clemente Pereira e padre Feijó. Ali foram arranjadas mais duas telas: uma, representando o episódio de expulsão das tropas portuguesas do Rio de Janeiro e outra, celebrativa da atuação dos deputa dos brasileiros nas cortes em Lisboa. ${ }^{15}$

Ainda no Saão Nobre há objetos e manuscritos expostos em vitrinas e dentre eles chamam especial atenção: porcelanas e relógios pertencentes à família imperia; bilhetes autografados por Da. Leopoldina e José Bonifácio; um capacete em latão da Guarda de Honra do primeiro imperador, que reproduz em dimensão tridimensional os capa cetes desenhados por Pedro Américo no conhecido paine; e madeixas das esposas de D. Pedro I e da princesa I sabel.

A disposição espacial de objetos, retratos e imagens que compõem a decoração interna revela uma proposta de comunicação com o público, que ainda é capaz de motivar entusiasmo ćvico, fruição estética e memorização. A narrativa histórica transformada em linguagem visual, ao menos nos moldes concebidos por Taunay, deve ria convencer homens e mulheres simples, e especialmente jovens escolares, da existência "real" das pessoas e dos eventos cuidadosamente selecionados para delinear a trajetória nacional. Neste sentido, o projeto de Taunay ancorava-se em uma concepção museológica bastante difundida em sua época e que, em certa medida, não foi totalmente superada, apesar do enorme debate que cerca as relações entre museus e ensino de história.

Nessa concepção, o museu deveria congregar coleções ordena das e classificadas, reunindo, além disso, coisas raras e úni cas (a exemplo da mecha de cabelos de Da Leopoldina) expostas com sabedoria para "instruir o olho a olhar". Sua importância maior estaria na conservação e exposição de "provas autênticas" das atividades e realizações humanas. Ou seja, os museus de história estariam destinados a promover a "visualização do passado como rẹlidade experiencial", conforme observou Stephen Bann, como se fosse possível traduzir em uma outra linguagem os manuais escolares. ${ }^{16}$ Daí o empenho de Taunay em coletar "monumentos" (testemunhos históricos fidedignos) e objetos portadores de "valores de época" (vestígios de um pas sado desaparecido). 
A questão é que "monumentos" e "valores de época" são emblemas de uma celebração. Não foram escol hidos e ali colocados para suscitar questionamentos a respeito do processo histórico da independência, mas para autenticar a memória da independência inscrita nas figuras e imagens que formam a decoração interna do prédio. Isso quer dizer que, no caso específico dessa temática, a visitação ao Museu Paulista significa sobretudo presenciar um "lugar de memória" no qual se entra em contato com uma representação singular do passado, fundada na sobreposição de duas temporalidades distintas: a da época em que o palácio-monumento foi construído e a do momento em que a ornamentação interna foi elaborada $O$ que se vê não é a história, e sim suportes visuais e físicos de uma memória que em torno do 7 de setembro foi criada e reedaborada.

Mas talvez resida aqui justamente uma possibilidade enrique cedora de incorporar o museu aos pressupostos que balizam o ensino fundamental e médio: por que não interrogar os sentidos dessa me mória, transformando-a em problema histórico sempre aberto a múltiplas releituras? E, nette sentido, por que não valorizar o museu como mais um espaço de reflexão no qual a convivência com objetos, com fontes históricas de natureza singular, aponte para outros referenciais de conhedimento?

\section{Notas}

1. CINTRA, F.A. D. Pedro I e o grito da independêndia; transcrição de documentos. São Paulo: Melhoramentos, 1921.

2. Ver sobre o assunto: OLIVEIRA, C.H.S. Independêndia e práticas liberais questões para debate São Paulo: IEA/USP, 1997.

3. A crônica do Padre Belchior foi reproduzida por Assis Cintra na obra já citada.

4. LISBOA, J.S. História dos prina pais sucessos do Império do Brasil. Rio de Janeiro: Tipografia Nacional e Imperial, 1827/1830.

5. O texto de Paulo do Valle foi reproduzido por Assis Cintra na obra mencionada. Quanto ao periódico O Polichinello, consultar a edição fac-similar publicada pelo Arquivo do Estado de S. Paulo, em 1986.

6. MARQUES, M.E.A. Apontamentos históricos, geográficos biogáficos etatísticos e noticiosos sobre a províndia de São Paulo. São Paulo; Belo Horizonte Itatiaia/Edusp, 1980. 2v.

7. NORA, P. (Dir.). Les lieux des mémoires Paris: Gallimard, 1984/85. 5v. Consultar especialmente $a$ introdução ao primeiro volume

8. Sobre o assunto consultar: SOUZA, I.L.S.C. Pátria coroada. São Paulo, UNESP, 1999.

9. Diário de D. Pedro II, 1862. Anuário do Museu Imperial. Perópolis MEC, 1956. v. 17. 
10. WRIGHT, M.R. The new Brazil (1902). Fragmentos da obra recolhidos por Ernani da Silva Bruno e editados no livro Memória da didade de São Paulo. São Paulo: Prefejtura Municipal/DPH, 1981.

11. FORREST, A.S. A tour through South America (1912). In: Bruno, E. S., ob. cit., p. 172-173.

12. IHERING, H. von. O Museu Paulista nos anos de 1910, 1911 e 1912. Revista do Musau Paulista, São Paulo, v.9, p. 8, 1914.

13. BITTEN COURT, C.M.F. Pátria, divilização e trabalho: o ensino de história nas escolas paulistas, 1917/1939. São Paulo: Loyola, 1990. Especialmente cap. 3.

14. VERÍSSIMO, J. Educação nacional. 3a ed. Porto Alegre Mercado Aberto, 1985. p. 101.

15. Sobre a decoração interna consultar: Guia da seção histórica do Museu Paulista. São Paulo: Imprensa Oficial, 1937.

16. BANN, S. As invenções da história. São Paulo: UNESP, 1994.

\section{Referênciasbibliográficas}

BITTENCOURT, C.M.F. (Org.). O saber histórico na sala de aula. $2^{\underline{a}}$ ed. São Paulo: Contexto, 1998.

MENESES, U.T.B. (Org.). Como explorar ummusau hi tárica São Paulo: Musen Paulista da USP, 1992.

OLIVEIRA, C.H.S. (Org.). Musau Paulista da usp: novas leituras. São Paulo: Museu Paulista/UsP, 1995.

WITTER, J.S.; BARBUY, H. (Org.). Musau Paulista, um monumento no I piranga. São Paulo: FIESP, 1997. 